\title{
Research on the Optimization of Industrial Structure Under Environmental Regulations-Taking Hubei Province as an Example
}

\author{
BeiQing Cui ${ }^{1 *}$, Can Zhang ${ }^{1}$ \\ ${ }^{1}$ Hubei Business College, No. 634 of Xiongchu Avenue, Hongshan District, Hubei Province, 430070, China \\ *Corresponding author. Email: 821949403@qq.com
}

\begin{abstract}
This article uses the statistical data of Hubei Province from 2004 to 2018 to conduct empirical analysis by constructing environmental regulation measurement indicators and industrial structure optimization models. The results show: foreign direct investment scale, economic development level, urbanization development level, and environmental regulation. The effect on the optimization of Hubei's industrial structure is different. Among them, environmental regulations, the scale of foreign direct investment and the level of urbanization development have a positive effect on the optimization of industrial structure; the relationship between industrial structure optimization and GDP growth rate is inversely proportional.
\end{abstract}

Keywords: Environmental regulation, Optimization of industrial structure, Hubei province.

\section{INTRODUCTION}

In 2018, Hubei Province completed a GDP of 3.936655 billion yuan, an increase of $7.8 \%$. Among them, the primary industry completed an added value of 354.751 billion yuan, an increase of $2.9 \%$; the secondary industry completed an added value of 1708.895 billion yuan, an increase of $6.8 \%$; the tertiary industry completed an added value of 187.309 billion yuan, an increase of $9.9 \%$. The structure of the three industries was adjusted from 10.0:43.5:46.5 in 2017 to 9.0:43.4:47.6. However, in 2018, Hubei Province's waste water discharge per unit of GDP was 6.42 tons/billion yuan, higher than 6.33 in Shandong Province and 6.27 in Jiangsu Province; SO2 discharge per unit GDP was 4.21 tons/billion yuan, much higher than Shandong's 2.25 and Zhejiang 2.22 in Jiangsu Province and 3.29 in Jiangsu Province.

Industrial structure optimization plays a decisive role in economic growth. Energy conservation and emission reduction are the only way to promote economic restructuring and transform the economic growth mode [1], and optimizing industrial structure is also an effective measure to promote the realization of energy conservation and emission reduction goals. Adjusting the industrial structure of Hubei Province and promoting the optimization and upgrading of the industrial structure are effective ways to alleviate the increasingly serious environmental problems. In the context of environmental regulation, what impact does environmental governance investment have on the optimization of Hubei's industrial structure? How to optimize and upgrade the industrial structure in the future, reduce environmental pressure, and achieve the coordination and integration of environmental regulation and industrial structure adjustment? This article will conduct a theoretical and empirical analysis of the above issues.

\section{CONSTRUCTION AND MEASUREMENT OF ENVIRONMENTAL REGULATION INDICATORS}

Constructing appropriate environmental regulation measurement indicators is the core of the article's research. Different research methods have different conclusions. Yang Lijun [2] used the VECM model to study the relationship between financial resource input and industrial structure optimization. Zhang $X$ et al. [3] used multi-objective optimization and adopted the NSGA-II algorithm for the industry in Northeast China. The structure is optimized for research, and the measurement methods used by domestic and foreign scholars on environmental regulation measurement mainly include: the number of environmental regulation policies and regulations promulgated, the number of 
supervision and inspections by environmental protection agencies, and the changes in pollutant discharge under environmental regulations [4]. In addition, Dasgupta research found that the income level of a country is highly correlated with the intensity of environmental regulations [5]; Xu research found that the intensity of environmental regulations has a significant correlation with GDP and GNP, that is, the intensity of environmental regulations is determined endogenously by income levels. Of [6]. Therefore, some scholars regard per capita income as an indicator of endogenous environmental regulation.

Based on the perspective of governance investment, this article selects the investment amount completed in wastewater treatment projects, the investment amount completed in waste gas treatment projects, and the investment amount completed in solid waste treatment projects as a proportion of the total investment in industrial pollution treatment. The average weights of the indicators are added together, and the intensity of environmental regulation is obtained as:

$$
\mathrm{ER}_{i}=\frac{1}{3} \sum_{j=1}^{3} X_{i j}
$$

$\mathrm{ER}_{i}$ Represents the intensity of environmental regulation $\mathrm{ER}_{i}$ in the $\mathrm{i}$-th year. The smaller the value, the less investment in the treatment of the "three wastes" and the stricter the environmental regulation; vice versa. $X_{i 1}$, $X_{i 2} 、 X_{i 3}$ Respectively indicate the proportion of the investment in wastewater treatment, waste gas treatment, and solid waste treatment in the total investment in industrial pollution treatment in the i year.

\section{INDUSTRIAL STRUCTURE OPTIMIZATION MODEL CONSTRUCTION AND DATA DESCRIPTION}

\subsection{Index selection}

(1) Industrial structure optimization index (Y). The industrial structure optimization measurement index draws on the research method of Zhou R. [7] and uses it $Y=\sum_{j}^{3} \gamma_{j} M_{j}$ to measure the level of industrial structure optimization. In the formula, $M_{j}$ represents the proportion of the $\mathrm{j}$-th industry's added value in the regional GDP, $\mathrm{j}$ is 1,2 , and $3 ; \gamma_{j}$ expresses the weight of the $\mathrm{j}$-th industry's added value in the proportion of regional GDP, the weight of the first industry is 1 , and the second industry The weight is 2 , and the tertiary industry is 3; $\mathrm{Y}$ represents the industrial structure optimization index, and the value range of $\mathrm{Y}$ is 1-3; the smaller the value of this index, the lower the industrial structure of a country or region, the larger the index, Which shows that the industrial structure of a country or region is higher.

(2) The scale of foreign direct investment (H1). Foreign direct investment is particularly important to the economic development of a certain region, and the technology spillover effect is very significant. Therefore, it has a significant impact on the industrial development of the region, especially the impact on the capitalintensive and technology-intensive industrial structure. The article uses the proportion of the total foreign direct investment in a certain region's GDP to express, that is $H_{1}=\frac{\text { FDI }}{\text { GDP }}$, in the formula, FDI represents the total foreign direct investment. The unit of the actual use of the original statistical data of foreign investment is 10,000 U.S. dollars, and the annual average exchange rate of RMB to U.S. dollars in the current year needs to be converted into 10,000 RMB for that year.

(3) The level of economic development (H2). The improvement of the level of economic development will promote the optimization and upgrading of the industrial structure. This article uses the reciprocal of the nominal GDP growth rate to express.

(4) Urbanization development level (H3). The development of urbanization in a region will cause the transfer of labor, which will lead to changes in the employment structure and thus affect the changes in the industrial structure. Therefore, the article uses the proportion of urban population in a certain area to the total population to express the level of urbanization development in that area.

\subsection{Model construction}

This article takes Hubei Province as an example to study the optimization of industrial structure under environmental regulation, and the data regression method is used for empirical testing. The industrial structure optimization and upgrading index $\mathrm{Y}$ is used as the explained variable. The explanatory variables are $\mathrm{H} 1, \mathrm{H} 2$, $\mathrm{H} 3$, and ER (environmental regulations). The following model (2):

$Y_{t}=C+\beta_{1} H_{1 t}+\beta_{2} H_{2 t}+\beta_{3} H_{3 t}+\beta_{4} E R_{t}+\mu$

Among them, $\mathrm{t}$ represents time, $\mathrm{Y}$ represents indicators of industrial structure optimization; ER represents indicators of environmental regulation; $\mathrm{H} 1$ represents foreign direct investment; $\mathrm{H} 2$ represents the level of economic development; H3 represents the process of urbanization, $\mu$ Represents random error.

\subsection{Data description}

This article analyzes the data of Hubei Province from 2004 to 2018. There are a total of 75 observations. The original data of each indicator comes from the "Statistical Yearbook of Hubei Province" and "China Statistical Yearbook". 
Table 1 The descriptive statistics of the variables

(Data source: Statistical Yearbook of Hubei Province、 Statistical Yearbook of China)

\begin{tabular}{|c|c|c|c|c|c|}
\hline & $\begin{array}{c}\text { YE } \\
\text { AYS }\end{array}$ & MIN & MAX & $\begin{array}{c}\text { AVERA } \\
\text { GE }\end{array}$ & $\begin{array}{c}\text { STDEV } \\
\text { A }\end{array}$ \\
\hline Y & 15 & 2.2259 & 2.4129 & 2.2804 & 0.0544 \\
\hline H1 & 15 & 0.0162 & 0.0333 & 0.0220 & 0.0056 \\
\hline H2 & 15 & 4.3110 & 12.6115 & 7.1618 & 2.6894 \\
\hline H3 & 15 & 0.4275 & 0.6030 & 0.5100 & 0.0636 \\
\hline H4 & 15 & 0.2239 & 0.3245 & 0.2917 & 0.0324 \\
\hline
\end{tabular}

\section{ANALYSIS OF EMPIRICAL RESULTS}

The empirical results are shown in the figure below. The estimated R2 of the model is 0.907 , and the adjusted $\mathrm{R} 2$ is 0.87 , indicating that the degree of fit is relatively

Table 2 Good, and passed the overall significance F test

(Note: $*, * *, * * *$ indicate that each variable is significant at $15 \%, 5 \%$, and $1 \%$ respectively)

\begin{tabular}{|c|c|c|}
\hline & $\mathrm{B}$ & $\mathrm{p}$ \\
\hline $\mathrm{C}$ & $1.389 * * *$ & 0.000 \\
\hline $\mathrm{H} 1$ & $7.621^{* * *}$ & 0.000 \\
\hline $\mathrm{H} 2$ & $-0.004^{*}$ & 0.147 \\
\hline $\mathrm{H} 3$ & $1.109^{* * *}$ & 0.000 \\
\hline $\mathrm{IS}$ & $0.643^{* *}$ & 0.013 \\
\hline \multicolumn{2}{|c|}{$\mathrm{F}=24.514 \quad \mathrm{R}=0.953$} & $\mathrm{R} 2=0.907$ \\
\hline
\end{tabular}

It can be seen from the regression results:

$Y=1.389+7.621 H_{1}-0.004 H_{2}+1.109 H_{3}+0.643 E R$

The scale of foreign direct investment (H1), economic development level (H2), urbanization development level (H3) and environmental regulations (ER) have different effects on the optimization of Hubei's industrial structure. Among them, the environmental regulation coefficient is positive and significant at the level of $5 \%$, indicating that environmental governance investment has a positive effect on the optimization of industrial structure, which is in line with expectations, indicating that governance investment promotes the upgrading of industrial structure. At the 5\% significance level, the current environmental regulation has no significant impact on the industrial structure, while the lagging one-stage environmental regulation has a significant impact on the industrial structure, indicating that environmental regulation has a time lag in its role.

The two control variables, the scale of foreign direct investment (H1) and the level of urbanization $(\mathrm{H} 3)$, are positively correlated with the optimization and upgrading of the industrial structure, and they have passed the $1 \%$ significance test. This shows that under the constraints of environmental regulations, the foreign direct investment and urbanization rate in Hubei have promoted the optimization of the industrial structure of Hubei Province, and the effect is significant, especially foreign direct investment, which has a significant role in promoting the optimization of the industrial structure of Hubei Province.

Through empirical analysis, the coefficient of the control variable economic development level $(\mathrm{H} 2)$ is negative, and it has passed the $15 \%$ significance test. The economic development level used in this study is the reciprocal of the nominal GDP growth rate, indicating that the optimization of the industrial structure and the GDP growth rate are inversely proportional, which from another aspect illustrates that part of the GDP is invested in environmental governance to promote the industrial structure of Hubei Province Optimization, which is also in line with expectations.

\section{CONCLUSIONS}

This paper uses the statistical data of Hubei Province from 2004 to 2018 to conduct empirical analysis by constructing environmental regulation measurement indicators and industrial structure optimization models. The results show that:

(1) Environmental regulations have promoted the optimization of the industrial structure of Hubei Province. Therefore, the government must adhere to the policy of environmental governance and increase the intensity of environmental governance in order to promote the optimization and upgrading of the industrial structure of Hubei Province. The empirical model will also find that there is an inverse relationship between GDP growth rate and industrial structure optimization, that is, excessive investment in environmental governance will affect the development of Hubei Province's GDP. Therefore, the government should take the actual situation into consideration, comprehensively consider local economic development under the premise of ensuring environmental regulations, and control investment in environmental governance within an appropriate range. It is necessary to further improve the enterprise exit mechanism, such as ordering high-energyconsuming enterprises to suspend business for rectification, and merging and reorganizing low-capacity enterprises, gradually phasing out high-energy, lowcapacity enterprises, transforming traditional production models, and forming a low-polluting "green" Industrial structure.

(2) The scale of foreign direct investment has played a significant role in promoting the optimization of Hubei's industrial structure. Hubei Province needs to further increase the attraction of foreign direct investment and promote the optimization and adjustment of the local industrial structure. Therefore, Hubei Province should attach great importance to foreign investment, introduce relevant policies to increase the scale of foreign direct investment, and ensure that foreign investment can "attract, survive, develop, and promote upgrade." 
However, one cannot blindly pursue the scale of foreign investment while ignoring quality. It is necessary to attract high-tech enterprises with low pollution and low energy consumption to further promote the optimization and upgrading of the industrial structure of Hubei Province.

(3) The level of urbanization development has played a huge role in promoting the optimization of Hubei's industrial structure, and provided sufficient development momentum for the optimization and adjustment of the industrial structure of Hubei Province. Therefore, it is necessary to vigorously promote the speed and progress of Hubei's urbanization development. The development of urbanization must adhere to the road of intensive development, focusing on reforms and promoting development, and avoid excessive pursuit of the speed and scale of urbanization development while ignoring the quality of urbanization development. Colleagues, the development of urbanization also needs to adapt to the new industrialization road with high technology, low pollution and low consumption.

Under environmental regulations, optimizing the industrial structure of Hubei Province is a long and gradual process. Therefore, in the specific implementation process, avoid overcorrecting environmental constraints and result in too many companies being eliminated due to a sharp increase in environmental costs, thus stagnating the upgrading of the industrial structure and even the deadlock of "industry reverse elimination".

\section{ACKNOWLEDGMENTS}

Research on the optimization of industrial structure in Hubei province under the regulation of resources and environment.

Hubei Business College

Item No. KY20191

\section{REFERENCES}

[1] Li H, Zou Q. Research on Environmental Regulation, Resource Endowment and Urban Industrial Transformation-Based on the Comparative Analysis of Resource-based Cities and Nonresource-based Cities. Economic Research, (2018) 11: 182-198.

[2] Yang L, Shao J. Re-estimation of China's regional industrial structure optimization. Quantitative Economics and Technical Economics Research, (2018) 10: 59-77.

[3] Zhang X, Tang X, Zhou S. Research on the optimization and adjustment of the manufacturing industry structure under the multiple constraints of environment, economy, and employment: Taking Northeast China as an example. Economic System Reform, (2019) 3: 86-93.

[4] Xia J, Jiao W. The evolution path and coupling effect analysis of industry and employment structure: Taking Shandong Province as an example. Economic Research, (2018) 10: 65-71.

[5] Dasgupta S, Mody A, Roy S, et al. Environmental regulation and development: a cross-country empirical analysis. Oxf Dev Studies, (2011) 2:173187.

[6] Xu X P. International Trade and Environment Policy: How Effective is "eco- dumping". Economic Modeling, (2015) 1:71-90.

[7] Zhou R. The impact of environmental regulations on the optimization and upgrading of the industrial structure in Anhui Province: An empirical analysis based on 16 cities in Anhui Province. East China Economic Management, (2017) 10: 16-20 